\title{
85644 - ACESSO A SERVIÇOS DE SAÚDE EM IDOSOS: UMA REVISÃO SISTEMÁTICA DE LITERATURA
}

\author{
Pôster - Gerontologia
}

\author{
Guilherme Briczinski de Souza / Souza, GB / UFCSPA; \\ Juliane Pinto Lucero / Lucero, JP / UFCSPA; \\ Eduardo Garcia / Garcia, E / UFCSPA
}

Introdução: O Brasil, juntamente com outros países, tem vivenciado o aumento acelerado do número de pessoas com mais de 60 anos de idade, desta forma à medida que a estrutura da população está mais envelhecida, a proporção de pessoas que utilizam os serviços de saúde aumenta. Portanto a disponibilidade de serviços, a distribuição geográfica, os mecanismos de financiamento dos serviços e a sua organização representam características que podem facilitar ou dificultar o acesso aos serviços de saúde para as pessoas idosas. Objetivo: Analisar as evidências cientificas publicadas sobre 0 acesso de pessoas idosas aos serviços de saúde. Método: Foi feita uma busca por artigos publicados de janeiro de 2009 a maio de 2019 nas bases de dados PubMed e Lilacs. Utilizaram-se os seguintes descritores (health services accessibility" OR "health services utilization" OR "access to health services") and ("elderly" OR "major adults" OR "older people" OR "aged" OR "older adults"). Os critérios de elegibilidade foram textos na forma de artigos científicos originais disponíveis on-line, na íntegra, que abordassem a temática nos idiomas português, inglês e espanhol. Resultados: A partir da combinação dos descritores, foram encontrados 1076 artigos, mas apenas 7 selecionados por se adequarem ao objetivo e fatores de inclusão. A maior parte dos estudos foi publicada em 2017 (42\%), predominando delineamentos transversal (42\%). Constatou-se entre os escolhidos, que alta escolaridade e renda estão associados com acesso a serviços de saúde por idosos fazendo a renda familiar influenciar na frequência de procura da assistência de saúde. Outro ponto está no fato do maior numero de consultas por parte dessa população e a alternativa de acesso com os serviços de home \& care. Foi evidenciado também que a população de mais de oitenta anos de idade precisa ter um acesso ampliado aos serviços de saúde e as limitações funcionais são um impedimento ao acesso a saúde, evidenciando maior dificuldade aos serviços públicos do que privados. Conclusão: Desta forma o poder de compra e o grau de escolaridade estão intimamente ligados ao acesso aos serviços de saúde, toda via, são os serviços privados que estão mais adaptados para a demanda do paciente idoso, isso devido as lacunas do serviço de saúde púbica e o descaso do poder público. 